\title{
Photofission Analysis for Fissile Dosimeters Dedicated to Reactor Pressure Vessel Surveillance
}

\author{
Stéphane Bourganel ${ }^{1, \mathrm{a}}$, Margaux Faucher ${ }^{2}$, and Nicolas Thiollay ${ }^{3}$ \\ ${ }^{1}$ CEA Saclay, DEN/DANS/DM2S/SERMA/LPEC, 91191 Gif-sur-Yvette Cedex, France \\ ${ }^{2}$ PHELMA, 3 Parvis Louis Néel - CS 50257, 38016 Grenoble Cedex 1, France \\ ${ }^{3}$ CEA Cadarache, DEN/DER/SPEx/LDCI, 13108 Saint Paul Lez Durance Cedex, France
}

\begin{abstract}
Fissile dosimeters are commonly used in reactor pressure vessel surveillance programs. In this paper, the photofission contribution is analyzed for in-vessel ${ }^{237} \mathrm{~Np}$ and ${ }^{238} \mathrm{U}$ fissile dosimeters in French PWR. The aim is to reassess this contribution using recent tools (the TRIPOLI-4 Monte Carlo code) and latest nuclear data (JEFF3.1.1 and ENDF/BVII nuclear libraries). To be as exhaustive as possible, this study is carried out for different configurations of fissile dosimeters, irradiated inside different kinds of PWR: $900 \mathrm{MWe}$, $1300 \mathrm{MWe}$, and $1450 \mathrm{MWe}$. Calculation of photofission rate in dosimeters does not present a major problem using the TRIPOLI- $4{ }^{\circledR}$ Monte Carlo code and the coupled neutron-photon simulation mode. However, preliminary studies were necessary to identify the origin of photons responsible of photofissions in dosimeters in relation to the photofission threshold reaction (around $5 \mathrm{MeV}$ ). It appears that the main contribution of high enough energy photons generating photofissions is the neutron inelastic scattering in stainless steel reactor structures. By contrast, ${ }^{137} \mathrm{Cs}$ activity calculation is not an easy task since photofission yield data are known with high uncertainty.
\end{abstract}

\section{Introduction}

Fissile dosimeters are commonly used in reactor pressure vessel surveillance programs. The ${ }^{238} \mathrm{U}$ and the ${ }^{237} \mathrm{~Np}$ threshold for the fission reaction is close to $1 \mathrm{MeV}$, which is a good indicator of the damage to the reactor pressure vessel. ${ }^{137} \mathrm{Cs}$, with a 30 years half-life, is usually the measured radio-isotope chosen to determine the fission rate for these dosimeters. There are three main ways to produce this radio-isotope:

- ${ }^{238} \mathrm{U}$ or ${ }^{237} \mathrm{~Np}$ isotopes fissions (main reactions).

- Fissile impurities fissions, such as ${ }^{235} \mathrm{U}$ in uranium dosimeters.

- Produced fissile isotopes fissions. ${ }^{239} \mathrm{Pu}$ is the principal example in uranium dosimeters.

The purpose of this study is to determine the proportion of fission induced by photofission in uranium and neptunium dosimeters using recent simulation tools, and the latest available nuclear data. To be

\footnotetext{
${ }^{a}$ Corresponding author: stephane.bourganel@cea.fr
}

This is an Open Access article distributed under the terms of the Creative Commons Attribution License 2.0, which permits unrestricted use, distribution, and reproduction in any medium, provided the original work is properly cited. 

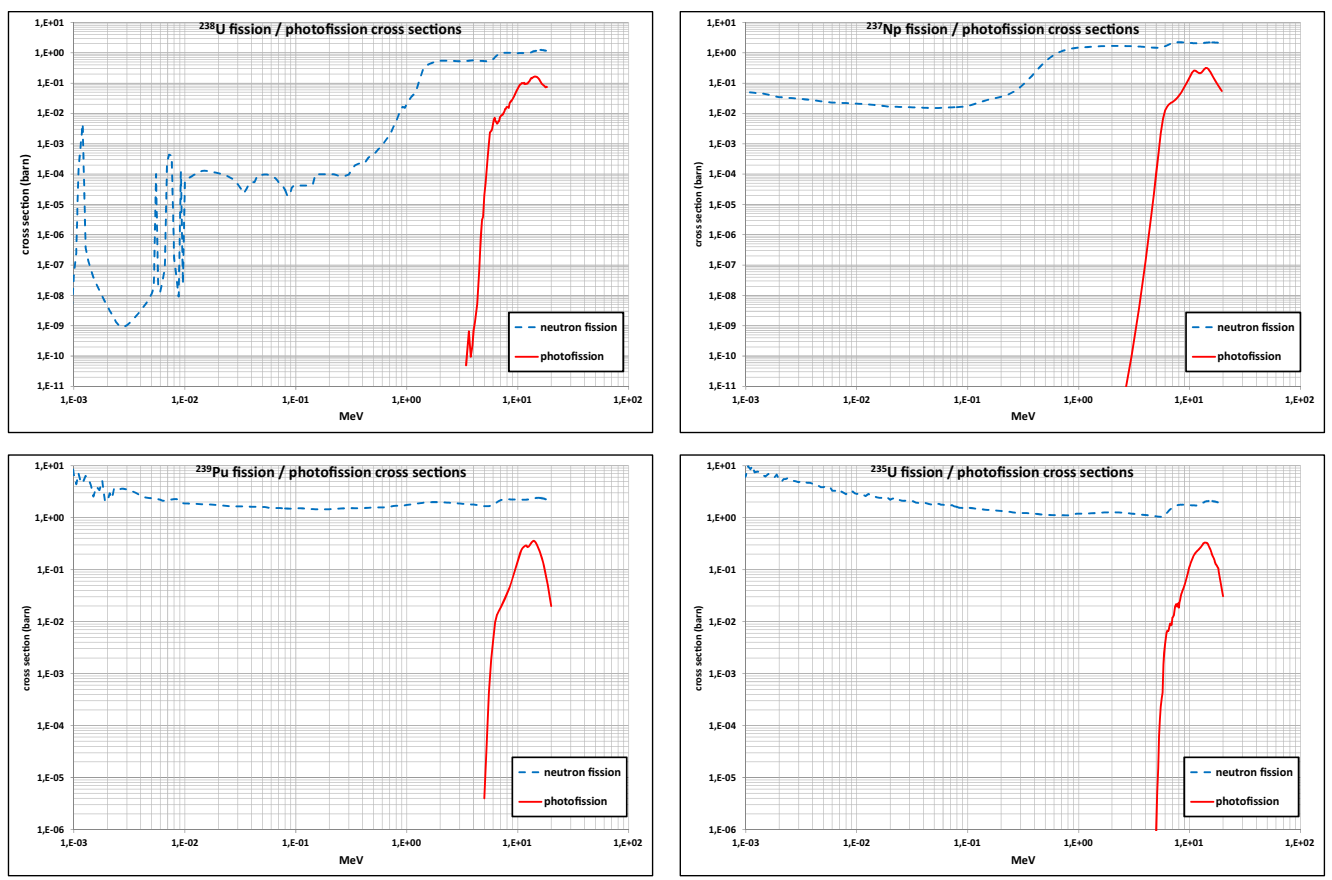

Figure 1. Photofission and neutron induced fission cross sections.

as exhaustive as possible, this study is carried out for different configurations of fissile dosimeters, irradiated inside different kinds of French PWR: 900 MWe, 1300 MWe, and 1450 MWe.

\section{Photofission}

Photofission cross sections, as well as neutron induced fission cross sections for ${ }^{238} \mathrm{U},{ }^{237} \mathrm{~Np},{ }^{235} \mathrm{U}$, and ${ }^{239} \mathrm{Pu}$, are presented in Fig. 1. Production of ${ }^{137} \mathrm{Cs}$ is principally due to these four isotopes. The origin of the neutron cross sections is IRDF2002 [1] since it is the reference dosimetry library for the French RPV surveillance program. A comparison between reaction rate values calculated with this library, and the recent IRDFF1.0 library was, however, carried out, and it did not show significant differences (less than, $1 \%$ ). For photofission reactions, cross sections are not available in the IRDF2002 library, so they come from the ENDF/B-VII nuclear library [2]. Two indications are provided by this figure: first photofission cross section for each fissile isotope is always lower than neutron induced fission cross section, and secondly photofission reaction thresholds are close to $5 \mathrm{MeV}$.

\section{Analyzed Configurations}

Fissile dosimeters are locked into a metal box, surrounded by a neutronic filter to reduce thermal reactions. This package is placed into a surveillance capsule to be irradiated in the reactor. French nuclear power plants consist of different kinds of capsules characterized by several types of fissile dosimeters, metal boxes, and neutronic filters. For each kind of reactor, these capsules are irradiated at different azimuthal positions. Fourteen fissile dosimeter configurations are analyzed (Table 1): 
Table 1. Fissile dosimeter configurations.

\begin{tabular}{|l|l|l|l|l|}
\hline Configuration name & 900-CD & 1300-CD & 1300-BN & 1450-BN \\
\hline Reactor power & $900 \mathrm{MWe}$ & $1300 \mathrm{MWe}$ & $1300 \mathrm{MWe}$ & $1450 \mathrm{MWe}$ \\
\hline $\begin{array}{l}\text { Number of azimuth positions } \\
\text { for the capsule irradiation }\end{array}$ & \multicolumn{1}{|c|}{2} & 4 & 4 & 4 \\
\hline Neutronic filter material & cadmium oxide & cadmium oxide & boron nitride & boron nitride \\
\hline Box material & nickel & nickel & titanium & titanium \\
\hline State of the fissile material & powder & powder & powder & spheres \\
\hline
\end{tabular}
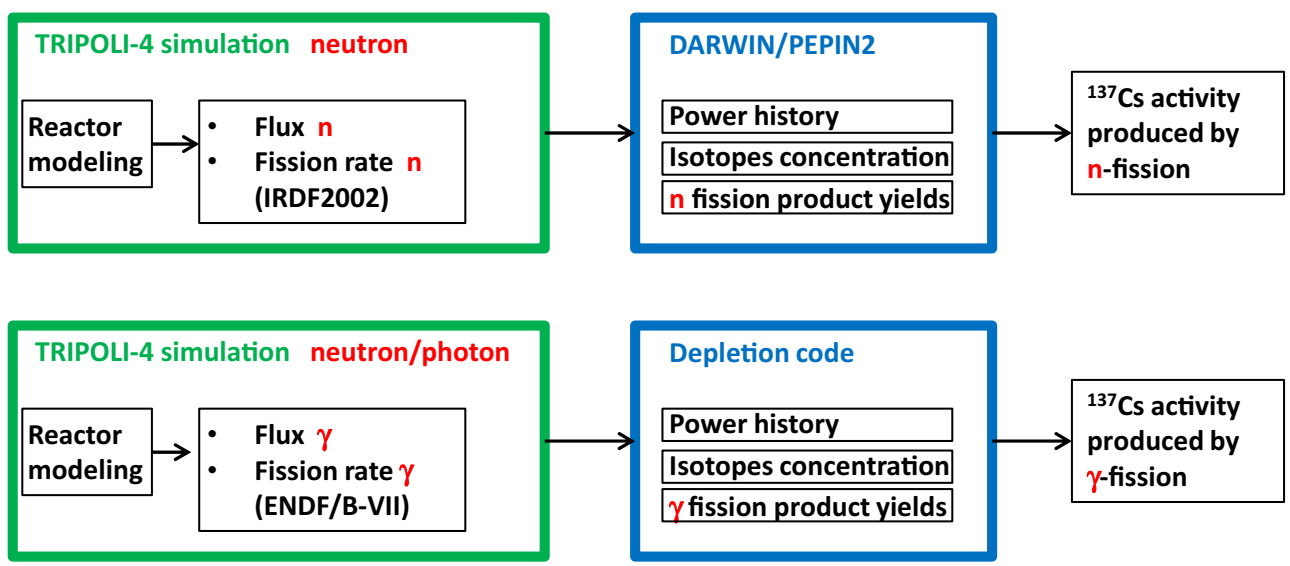

Figure 2. Calculation scheme.

\section{Calculation Scheme}

The ${ }^{137} \mathrm{Cs}$ total activity is calculated in two steps. The reaction rates are first calculated for all fissile isotopes in the dosimeters. The ${ }^{137} \mathrm{Cs}$ activity is then calculated using a depletion code with reaction rate values, the initial isotope concentration, and a power history. The ${ }^{137} \mathrm{Cs}$ activity from neutron induced fission and photofission are calculated separately as shown in Fig. 2.

Four different power histories are taken into account: 1 cycle, 4 cycles, 9 cycles, and 14 cycles. A one cycle power history corresponds to experiments in a PWR reactor such as the H.B. Robinson-2 experiment [3] (benchmark referenced in the SINBAD data bank [4]). The three other power histories are representative of average durations of irradiation for standard surveillance capsules in French PWR's.

\subsection{Fission Rate Calculation}

Both neutron induced fission rate and photofission rate are calculated using the TRIPOLI- $4{ }^{\circledR}$ Monte Carlo code [5]. TRIPOLI- $4{ }^{\circledR}$ is a $3 \mathrm{D}$ transport code using full pointwise cross section data. It is dedicated to radiation protection and shielding, nuclear criticality safety, fission and fusion reactor design, and nuclear instrumentation. It is used as a reference tool by CEA, EDF, and several other industrial or institutional partners.

The neutron fission rate as well the photofission rate is calculated for four fissile isotopes: ${ }^{238} \mathrm{U}$, ${ }^{237} \mathrm{~Np},{ }^{235} \mathrm{U}$, and ${ }^{239} \mathrm{Pu}$. Several cross section libraries are used in this study. The JEFF3.1.1 library [6] is dedicated to neutron and photon transport. The IRDF2002 library is dedicated to neutron fission rate calculation, and the ENDF/B-VII library is used for photofission rate calculation.

The neutron induced fission rate is calculated inside each fissile dosimeter. A specific variance reduction technique is used to reduce the simulation time and to increase its efficiency. The variance 
Table 2. $\mathrm{F}_{\gamma}$ factor for the 900-CD configuration.

\begin{tabular}{|c|c|c|c|c|}
\hline \multirow{2}{*}{ Azimuth } & \multirow{2}{*}{ Power histories } & Uranium dosimeters & Uranium dosimeters & Neptunium dosimeters \\
\cline { 3 - 5 } & & ABLA fission yield & JEFF3 fission yield & JEFF3 fission yield \\
\hline \multirow{4}{*}{ Azimuth 1 } & 1 cycle & 0.977 & 0.979 & 0.994 \\
\cline { 2 - 5 } & 4 cycles & 0.979 & 0.981 & 0.994 \\
\cline { 2 - 5 } & 9 cycles & 0.982 & 0.983 & 0.994 \\
\cline { 2 - 5 } & 14 cycles & 0.984 & 0.985 & 0.995 \\
\cline { 2 - 5 } Azimuth 2 & 1 cycle & 0.978 & 0.979 & 0.995 \\
\cline { 2 - 5 } & 4 cycles & 0.979 & 0.981 & 0.995 \\
\cline { 2 - 5 } & 9 cycles & 0.981 & 0.983 & 0.995 \\
\cline { 2 - 5 } & 14 cycles & 0.983 & 0.995 \\
\hline
\end{tabular}

reduction scheme in the TRIPOLI- $4{ }^{\circledR}$ code allows an automatic pre-computation of the importance $\operatorname{map} \operatorname{Iref}(\mathrm{P})$.

To calculate the photofission rate, a preliminary study was carried out to determine the photons origin producing photofissions in the fissile dosimeters in relation to the photofission reaction threshold (around $5 \mathrm{MeV}$ ). There are four main photon sources in a PWR in operation:

- Photon emission from fissions in the core.

- Photon emission from fission products in the core.

- Photon emission from activated elements in the reactor (water, stainless-steel structures).

- Photon emission from inelastic scattering of neutrons in the reactor.

Photon emissions from the core (fissions and fission products) are negligible due to both the distance between the core and the fissile dosimeters and their low energy. Contribution of photons emitted from activated elements in the reactor (metal structures and water) is also negligible since their intensity is too low. Photon emission from inelastic scattering of neutrons in the reactor, and photons produced by neutron absorption, in particular in the vicinity of the dosimeters (cadmium or boron filter, box, ... ), are the only contributions which must be taken into account. A coupled neutron-photon simulation using the TRIPOLI- $4^{\circledR}$ code allows the determination of this photon emission source.

\section{2 ${ }^{137}$ Cs Activity}

The ${ }^{137} \mathrm{Cs}$ activity is calculated using a depletion code, and the following data: reaction rate values from the TRIPOLI- $4{ }^{\circledR}$ simulations, initial isotopes concentrations, and a power history related to the studied reactor. For neutron induced fissions, the DARWIN/PEPIN2 depletion code [7] is used. This code solves Bateman's generalized differential equations governing the time dependence of isotope concentrations. It may be coupled with the TRIPOLI- $4{ }^{\circledR}$ code. Fission yield values used to calculate ${ }^{137} \mathrm{Cs}$ activity are derived from the JEFF3.1.1 nuclear data library.

For the photofission, a specific depletion program has been developed to calculate ${ }^{137} \mathrm{Cs}$ activity. In this program, only the nuclear data useful to calculate the ${ }^{137} \mathrm{Cs}$ activity from the ${ }^{238} \mathrm{U},{ }^{237} \mathrm{~Np},{ }^{235} \mathrm{U}$, and ${ }^{239} \mathrm{Pu}$ isotopes have been implemented: fission yields, half-lives, and branching ratios. Fission yields for ${ }^{238} \mathrm{U}$ are derived from the use of the ABLA code [8]. For other fissile isotopes, fission yield values come from the JEFF3.1.1 library since they are not available using the ABLA code. The use of JEFF3.1.1 yield values is discussed in the results analysis in Sect. 5.

\section{Results and Discussion}

The photofission contribution is represented by the $F_{\gamma}$ factor defined as $F_{\gamma}=A_{n} /\left(A_{n}+A_{\gamma}\right)$ where:

- $A_{n}$ represents the ${ }^{137}$ Cs activity induced by neutron induced fissions.

- $\mathrm{A}_{\gamma}$ stands for the ${ }^{137} \mathrm{Cs}$ activity induced by photofissions. 


\section{$15^{\text {th }}$ ISRD}

Table 3. $\mathrm{F}_{\gamma}$ factor for the 1300-CD configuration.

\begin{tabular}{|c|c|c|c|c|}
\hline \multirow{2}{*}{ Azimuth } & \multirow{2}{*}{ Power histories } & Uranium dosimeters & Uranium dosimeters & Neptunium dosimeters \\
\hline & & ABLA fission yield & JEFF3 fission yield & JEFF3 fission yield \\
\hline \multirow{4}{*}{ Azimuth 1} & 1 cycle & 0.973 & 0.975 & 0.992 \\
\hline & 4 cycles & 0.974 & 0.976 & 0.992 \\
\hline & 9 cycles & 0.975 & 0.977 & 0.992 \\
\hline & 14 cycles & 0.977 & 0.978 & 0.992 \\
\hline \multirow{4}{*}{ Azimuth 2} & 1 cycle & 0.975 & 0.977 & 0.992 \\
\hline & 4 cycles & 0.976 & 0.978 & 0.992 \\
\hline & 9 cycles & 0.977 & 0.979 & 0.992 \\
\hline & 14 cycles & 0.978 & 0.980 & 0.992 \\
\hline \multirow{4}{*}{ Azimuth 3} & 1 cycle & 0.974 & 0.976 & 0.992 \\
\hline & 4 cycles & 0.975 & 0.977 & 0.992 \\
\hline & 9 cycles & 0.977 & 0.979 & 0.993 \\
\hline & 14 cycles & 0.979 & 0.980 & 0.993 \\
\hline \multirow{4}{*}{ Azimuth 4} & 1 cycle & 0.973 & 0.976 & 0.992 \\
\hline & 4 cycles & 0.975 & 0.977 & 0.992 \\
\hline & 9 cycles & 0.977 & 0.978 & 0.993 \\
\hline & 14 cycles & 0.978 & 0.980 & 0.993 \\
\hline
\end{tabular}

Table 4. $\mathrm{F}_{\gamma}$ factor for the 1300-BN configuration.

\begin{tabular}{|c|c|c|c|c|}
\hline \multirow{2}{*}{ Azimuth } & \multirow{2}{*}{ Power histories } & Uranium dosimeters & Uranium dosimeters & Neptunium dosimeters \\
\cline { 2 - 5 } & & ABLA fission yield & JEFF3 fission yield & JEFF3 fission yield \\
\hline \multirow{4}{*}{ Azimuth 1 cycle } & 0.974 & 0.976 & 0.992 \\
\cline { 2 - 5 } & 4 cycles & 0.974 & 0.976 & 0.992 \\
\cline { 2 - 5 } & 9 cycles & 0.974 & 0.976 & 0.992 \\
\cline { 2 - 5 } Azimuth 2 cycles & 0.974 & 0.976 & 0.992 \\
\cline { 2 - 5 } & 1 cycle & 0.973 & 0.975 & 0.992 \\
\cline { 2 - 5 } & 4 cycles & 0.973 & 0.975 & 0.992 \\
\cline { 2 - 5 } & 9 cycles & 0.973 & 0.976 & 0.992 \\
\cline { 2 - 5 } Azimuth 3 cycles & 0.974 & 0.976 & 0.992 \\
\cline { 2 - 5 } & 1 cycle & 0.974 & 0.976 & 0.992 \\
\cline { 2 - 5 } & 4 cycles & 0.974 & 0.976 & 0.992 \\
\cline { 2 - 5 } & 9 cycles & 0.975 & 0.977 & 0.992 \\
\hline \multirow{4}{*}{ Azimuth 4 cycles } & 0.975 & 0.974 & 0.992 \\
\cline { 2 - 5 } & 14 cycle & 0.972 & 0.974 & 0.992 \\
\cline { 2 - 5 } & 9 cycles & 0.972 & 0.975 & 0.992 \\
\cline { 2 - 5 } & 14 cycles & 0.973 & 0.975 & \\
\hline
\end{tabular}

For each kind of fissile dosimeter, the $\mathrm{F}_{\gamma}$ factor is applied to the ${ }^{137} \mathrm{Cs}$ measured activity values in order to deduce the photofission effect. Tables 2 to 5 present the $\mathrm{F}_{\gamma}$ factor for $900-\mathrm{CD}, 1300-\mathrm{CD}$, $1300-\mathrm{BN}$, and 1450-BN configurations respectively.

These Tables show that the $\mathrm{F}_{\gamma}$ factors associated to uranium dosimeters are not sensitive to the fission yield origin (ABLA or JEFF3). The low contribution of photofission for these dosimeters (less than 3\%) explains this result.

The $\mathrm{F}_{\gamma}$ factor average values for each reactor configuration are gathered in Fig. 3.

For neptunium dosimeters, and for each configuration, the $\mathrm{F}_{\gamma}$ factors are constant regardless of the power history. The presented values are average values from 1 to 14 irradiation cycles.

Conversely, the $\mathrm{F}_{\gamma}$ factors for uranium dosimeters are slightly dependent on the power history. These variations are represented graphically on Fig. 3. However, these variations depend on the neutronic filter compound: dependence on power history is more important using a cadmium filter (CD) than a boron nitride filter $(\mathrm{BN})$. A boron nitride filter is more efficient to reduce the thermal flux than an oxide 
Table 5. $\mathrm{F}_{\gamma}$ factor for the 1450-BN configuration.

\begin{tabular}{|c|c|c|c|c|}
\hline \multirow{2}{*}{ Azimuth } & \multirow{2}{*}{ Power histories } & Uranium dosimeters & Uranium dosimeters & Neptunium dosimeters \\
\hline & & ABLA fission yield & JEFF3 fission yield & JEFF3 fission yield \\
\hline \multirow{4}{*}{ Azimuth 1} & 1 cycle & 0.972 & 0.974 & 0.992 \\
\hline & 4 cycles & 0.972 & 0.975 & 0.992 \\
\hline & 9 cycles & 0.973 & 0.975 & 0.992 \\
\hline & 14 cycles & 0.973 & 0.975 & 0.992 \\
\hline \multirow{4}{*}{ Azimuth 2} & 1 cycle & 0.973 & 0.975 & 0.993 \\
\hline & 4 cycles & 0.973 & 0.975 & 0.993 \\
\hline & 9 cycles & 0.973 & 0.975 & 0.993 \\
\hline & 14 cycles & 0.974 & 0.976 & 0.993 \\
\hline \multirow{4}{*}{ Azimuth 3} & 1 cycle & 0.971 & 0.974 & 0.993 \\
\hline & 4 cycles & 0.972 & 0.974 & 0.993 \\
\hline & 9 cycles & 0.972 & 0.974 & 0.993 \\
\hline & 14 cycles & 0.972 & 0.974 & 0.993 \\
\hline \multirow{4}{*}{ Azimuth 4} & 1 cycle & 0.973 & 0.975 & 0.992 \\
\hline & 4 cycles & 0.974 & 0.976 & 0.992 \\
\hline & 9 cycles & 0.974 & 0.976 & 0.992 \\
\hline & 14 cycles & 0.974 & 0.976 & 0.992 \\
\hline
\end{tabular}

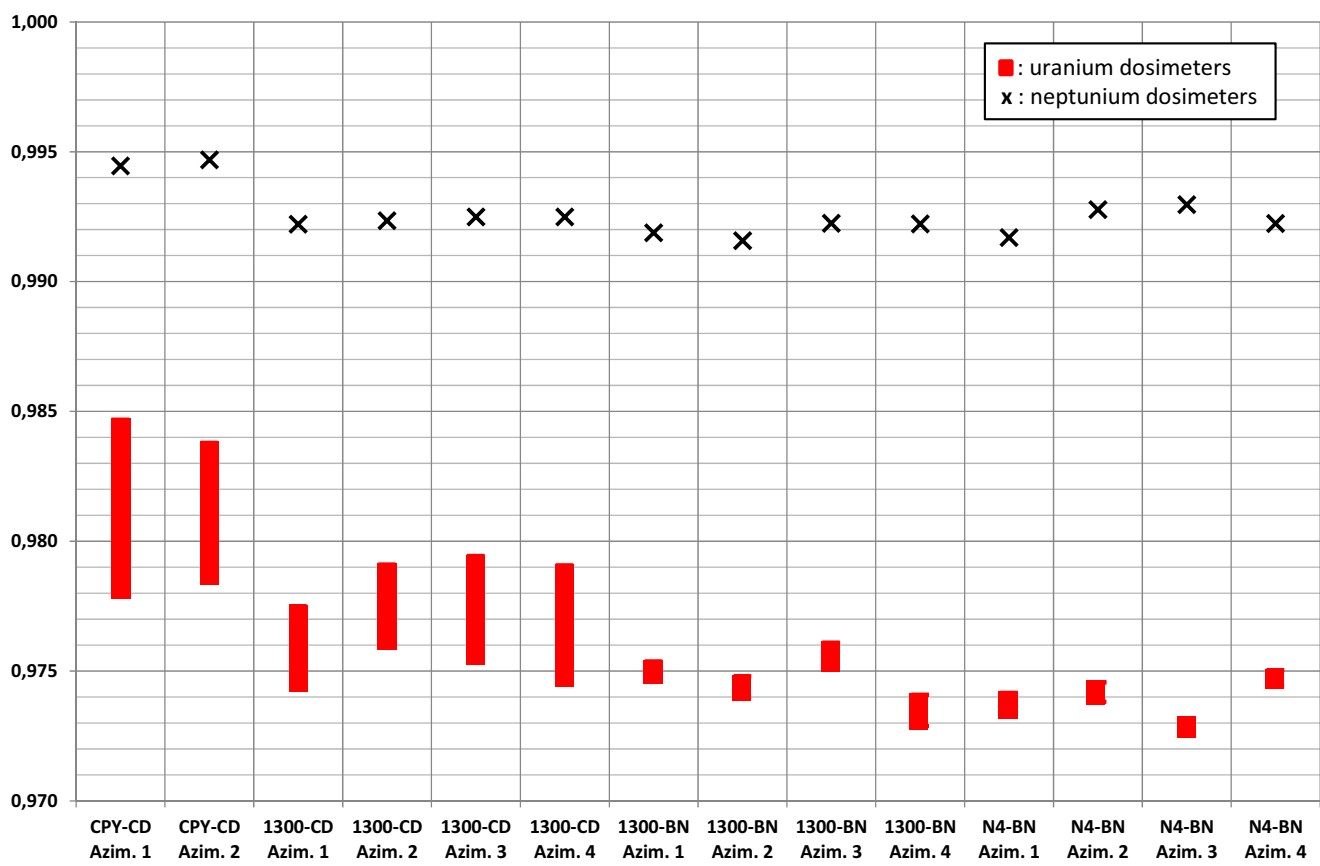

Figure 3. Summary of the $\mathrm{F}_{\gamma}$ factors.

cadmium one. Therefore, the contribution of ${ }^{239} \mathrm{Pu}$ in the overall fission decreases by the use of this material, which explains this result.

In addition, the $\mathrm{F}_{\gamma}$ factors for both neptunium and uranium dosimeters are slightly higher for the 900-CD configurations. This variation may result from the difference between the $900 \mathrm{MWe}$ capsule configuration on the one hand, and both the 1300 and 1450 MWe capsule configurations on the other hand, as shown in Fig. 4. 


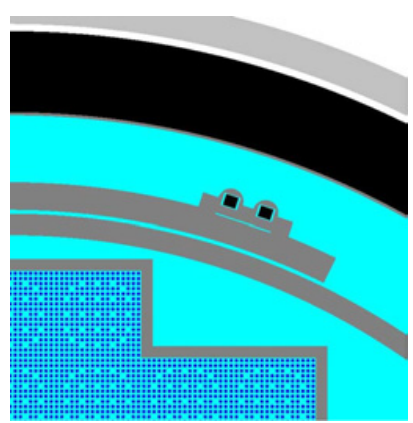

$900 \mathrm{MWe}$

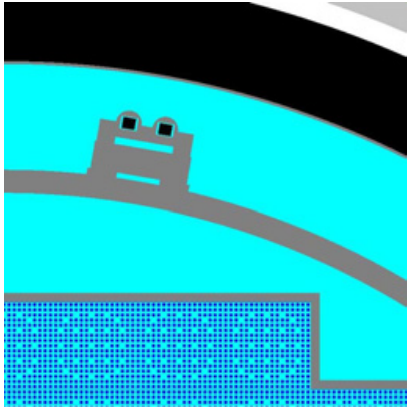

$1300 \mathrm{MWe}$

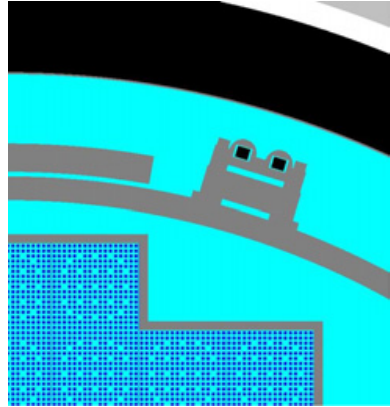

$1450 \mathrm{MWe}$

Figure 4. Capsule configurations.

The considered value for each kind of fissile dosimeter is the mean value for each type of reactor, whatever the power history is. A low discrepancy between these results allows this simplification:

- Uranium dosimeters: $0.976 \pm 0.003$.

- Neptunium dosimeters: $0.993 \pm 0.001$.

These results are much higher than usual results from different international benchmarks. For instance, data associated to the H.B. Robinson-2 benchmark [3] suggest that measured ${ }^{137}$ Cs activity values should be reduced by $2.5 \%$ and $5 \%$ respectively in order to compensate for the photofission contribution for in-vessel dosimeters. This means a correction factor between 0.950 and 0.975 .

\section{Conclusion}

A photofission analysis is presented in this paper. The aim is to determine this phenomenon contribution to ${ }^{137} \mathrm{Cs}$ activity of fissile dosimeters irradiated in PWRs. This analysis has been carried out using recent simulation tools (TRIPOLI-4 ${ }^{\circledR}$, DARWIN/PEPIN2), and the latest available nuclear data (JEFF3.1.1, ENDF/B-VII). This analysis leads to apply two single factors to deduce the photofission effect in ${ }^{137} \mathrm{Cs}$ measured activity. An additional uncertainty is added to the ${ }^{137} \mathrm{Cs}$ measured activity values. This uncertainty does not represent the total uncertainties on the $\mathrm{F}_{\gamma}$ factors, but the discrepancy between all $\mathrm{F}_{\gamma}$ factor values. It represents the error when only one average value is considered (as suggested in this article) instead of all individual values for each studied case.

For the uranium dosimeter, an experimental analysis will be carried out: a couple of dosimeters will be dissolved to evaluate, among other things, the total fission rate (neutron induced fission and photofission). A partial validation would be provided by a comparison between these experimental results and calculations.

Relevant values and their discrepancy are presented in Table 6:

Table 6. $\mathrm{F}_{\gamma}$ factors.

\begin{tabular}{|l|l|}
\hline Uranium dosimeters & $0.976 \pm 0.3 \%$ \\
\hline Neptunium dosimeters & $0.993 \pm 0.1 \%$ \\
\hline
\end{tabular}

The authors take the opportunity to thank gratefully EDF for its support, as well as the DSM/IRFU/SPhN/LEARN and the DRT/LIST/DM2I/LCAE laboratories (CEA/Saclay) for their helpful advice. 


\section{References}

[1] International Reactor Dosimetry File 2002, Technical reports series n ${ }^{\circ} 452$, IAEA

[2] M.B. Chadwick et al, ENDF/B-VII.1 Nuclear Data for Science and Technology: Cross Sections, Covariances, Fission Product Yields and Decay Data, Nuclear data sheets 112 Issue 12 (2011), Pages 2887-2996

[3] I. Remec, F.B. Kam, H.B. ROBINSON-2 pressure vessel benchmark, NUREG/CR-6453; ORNL/TM-13204, O.R.N.L., 1997

[4] OECD/NEA, 2006b. SINBAD REACTOR, shielding benchmark experiments, website: http://www.nea.fr/abs/html/nea-1517.html

[5] TRIPOLI-4 ${ }^{\circledR}$ Project Team, Overview of TRIPOLI-4 version 7 Continuous-energy Monte Carlo Transport Code, ICAPP 2011, May 2nd-5th, Nice, France

[6] A. Santamarina et al, The JEFF-3.1.1 Nuclear Data Library, COECD 2009 - NEA No. 6807

[7] A. Tsilanizara et al, Experimental validation of the DARWIN2.3 package for fuel cycle applications, PHYSOR 2012, Knoxville, Tennessee, USA, April 15-20, 2012

[8] J. Benlliurea et al, Calculated nuclide production yields in relativistic collisions of fissile nuclei, Nuc. Ph. 628 issue 3 (1998), Pages 458-478 